\title{
Puerta al tiempo en tres voces
}

\author{
POEMA DE LUIS PALES MATOS
}

¿Qué lenguaje te encuentra, con qué idioma (Ojo inmóvil, voz muda, mano laxa)

Podré yo asirte, columbrar tu imagen...?

PALÉs Matos, Puenta al tiempo...

I UIs Palés Matos, poeta puertorriqueño y una de las más cido en los ámbitos hispanoparlantes por su poesía negroide que él denomina "afroantillana". ${ }^{1}$ Críticos de la autoridad de Ángel Balbuena Prat, Federico de Onís, Margot Arce, Tomás Blanco, Andrés Iduarte, Eugenio Florit, etc., se han ocupado en forma elogiosa de este aspecto de su obra desde el momento mismo de su aparición, dándole a conocer fuera de los estrechos límites de Puerto Rico. Gran parte de la producción de nuestro poeta, tanto anterior como posterior a su poesía negroide, y con ella, posiblemente, mucho de lo mejor de su obra, permanece todavía, sin embargo, inédita. Uno de estos poemas, no recogidos aún en libro por su autor, ha visto la luz pública en una obra de carácter didáctico. ${ }^{2}$ Se trata del extra-

1 Luis Palés Matos, Tuntún de pasa y grifería. Poemas afroantillanos, (San Juan, Puerto Rico, Biblioteca de Autores Puertorriqueños, 1937) [Hay una segunda edición, de la misma editorial, de 1950].

2 Universidad de Puerto Rico, Facultad de Estudios Generales, Lecturas en lengua española, (Antología), (Santurce, Puerto Rico, Imprenta Soltero, 1951), p. $275-278$. 
ordinario poema Puerta al tiempo en tres voces, poema que desde la primera vez que lo leí me causó una profundísima impresión, que no ha menguado con el transcurso del tiempo y las repetidas lecturas que de él he hecho. Al análisis de este poema quiero dedicar las breves páginas de este ensayo.

\section{TÍTULO Y TEMA}

El tiempo, lo sabemos - ninguna época ha estado tan angustiosamente consciente de ello como la nuestra- es el gran "omnicida". Nada, en este mundo de creaturas, escapa a sus efectos. Unas cosas las destruye, las aniquila; otras, las arruina; a todas las cambia, las transforma. $Y$ no es ello menos cierto en lo psíquico que en lo físico. El tiempo, a medida que pasa, se va llevando consigo buena parte de nuestras ilusiones, de nuestras esperanzas, de nuestras convicciones, de nuestros recuerdos. A la labor destructiva del tiempo en nuestra memoria damos el nombre de olvido: el tiempo es el más eficaz agente de olvido. Como esas fotografías de las cuales la acción del hiposulfito no eliminó todo trazo de nitrato de plata y luego se van amarilleando según pasa el tiempo, las imágenes e impresiones de nuestra memoria, en un principio nítidas y claras, se van desdibujando, difuminando, hasta terminar por hacerse completamente borrosas e irreconocibles. Un día nos sorprendemos de no poder recordar con precisión los rasgos faciales de una persona con la que convivimos durante años, pero de quien nos separó, hace tiempo, la distancia o la muerte; o el timbre de voz de un ser muy querido pero ido ya para siempre desde hace mucho. El encuentro con personas que hace tiempo no veíamos, nos hace patentes cuántas cosas tenemos completamente olvidadas. A veces, mediante un esfuerzo, tratamos de salvar ese pasado, ese "tiempo perdido", haciendo un ejercicio de memoria voluntaria, y fijándolo en una obra de arte. Tenemos entonces un "tiempo recobrado", salvado del olvido, eternizado, por medio de la obra artística. Cada vez que lo logramos, estamos abriendo una puerta al tiempo; puerta que no puede dar a otra parte que al no-tiempo, a lo intemporal, a lo eterno. Al tiempo no le podemos anular 
más que con la eternidad; sólo a ella es posible escapar de él; y quien desespere de lograrlo en el orden sobrenatural, todavía tiene la puerta del arte y la belleza, para lograrlo en el natural.

Puerta al tiempo en tres voces es el intento de salvar de los efectos destructores del tiempo, el recuerdo amado de un ser querido. El poeta, angustiosamente consciente de los efectos evanescentes del tiempo, quiere fijar esa imagen, eternizarla, en tres cantos - voces_que son como llamadas, como conjuros, a que la imagen querida recobre su nitidez y firme definición evocada por tres vías distintas: el sueño, la palabra, el pensamiento. Pero todo es inútil: la imagen amada resulta inaprehensible. Ni la fantasía onírica, ni la palabra afectiva, ni el pensamiento evocador pueden asir la imagen (impresión en el recuerdo) de su imagen (impresión actual cuando existía). Y el poeta queda, preso en su angustia, profundamente herido en lo más hondo de su ser: "Yo evaporado, diluído, roto,/Abierta red en el sinfín sin fondo..."

El poema expresa, pues - y ése es su tema central- la angustia del hombre sensible ante la incapacidad de nuestros medios psíquicos para salvar de los efectos del tiempo un recuerdo dolorosamente amado. Pero al mismo tiempo, y como contrapeso, se expresa la confianza en el poder salvador del arte, de la poesía. La fantasía onírica, el lenguaje afectivo y el pensamiento imaginativo habrán sido incapaces de conjurar la imagen amada, pero en el proceso de intentarlo se ha creado un bello poema que es, al fin y al cabo, otro modo de salvarla del olvido.

\section{ESTRUCTURA DEL POEMA}

Puerta al tiempo en tres voces está dividido en tres cantos, "tres voces" que abarcan un total de nueve estrofas. Cada canto es como un llamado, como un conjuro, que trata de evocar la imagen del ser amado desaparecido. El primer canto, de cuatro estrofas, que contiene los escasos elementos factuales, anecdóticos, del poema, es la evocación inconsciente, en el sueño, de la amada muerta. El segundo, de dos estrofas, es un intento consciente, pero fallido, de aprehenderla mediante la palabra. $\mathrm{Y}$ el tercero, de tres estrofas, también consciente 
y fallido, de evocarla mediante el pensamiento imaginativo. En conjunto, constituyen una "acción frustrada" en cuanto a su propósito inmediato de conjurar la presencia de la amada; pero, al mismo tiempo, por la gracia del arte, una forma salvadora del recuerdo que angustiosamente se va desdibujando en la memoria.

\section{CANTO PRIMERO: ANGUSTIA DE LA FANTASÍA OÑÍRICA}

El primer canto es la "voz" del sueño. En sueños, la memoria inconsciente conjura la presencia de la imagen desaparecida. Y la imagen acude; pero acude alucinantemente transformada por la fantasía inconsciente. La Filí Melé que acude es una mujer-mito, una nueva Dafne o Sirenusa, una mujerárbol (estrofa 1). Y con ella, las circunstancias de su muerte (estrofa 2) y la angustia del poeta ante la incertidumbre de su destino final (estrofas 3-4).

Se inicia el poema "in media res", sin preparación de clase alguna, con una oración que es fragmento de sí misma y que, por lo mismo, comienza con puntos suspensivos y minúscula. Da la impresión, de ese modo, de que el primer canto es fragmento de un todo mayor, en cuyo resto estarían, quizás, los antecedentes que harían luz sobre lo que tenemos. Y a seguidas de esta primera oración fragmentaria que nos informa del carácter onírico de lo que sigue, aparece la imagen de FiliMelé como mujer-árbol, dorada y transparente:

\section{I}

...del trasfondo de un sueño la escapada

Filí-Melé. La flúida cabellera

Fronda crece, de abejas enjambrada;

El tronco - desnudez cristalizada-

Es desnudez en luz tan desnudada.

Que al mirarlo se mira la mirada. (Estr. 1)

La segunda estrofa, al evocar las circunstancias de la muerte de "la escapada", sugiere una muerte por propia determinación mediante el clásico desangramiento: 
Frutos hay y la vena despertada

Látele azul y en el azul diluye

Su pálida tintura derramada,

Por donde todo hacia la muerte fluye

En huída tan lueñe y sosegada

Que nada en ella en apariencia huye. (Estr. 2)

Y las dos últimas estrofas expresan la angustia de desconocer el destino final de esta mujer misteriosa que no parecía cosa de este mundo de espacio y tiempo. Acudiendo una vez más a reminiscencias mitológicas, el poeta la ve cruzando en barca (¿Caronte?) los mares (¿Estigia? ¿Leteo?) que la conducen al reino de la muerte:

Filí-Melé, Filí-Melé, hacia dónde Tú, si no hay tiempo para recogerte $\mathrm{Ni}$ espacio donde puedas contenerte? Fili, la inapreciable ya atrapada, Melé, numen y esencia de la muerte. (Estr. 3)

$\mathrm{Y}$ ahora ¿a qué trasmundo, perseguida, Serás, si es que eres? ¿Para qué riberas Huye tu blanca vela distendida

Sobre mares oleados de quimeras? (Estr. 4)

Dos dudas tremendas desgarran al poeta ante el umbral de esta puerta hacia el misterio que abre la muerte de su amada: ¿A qué trasmundo perseguida? Es decir, ¿a qué lugar o estado del más allá - infierno, purgatorio-irá castigada - "perseguida" esta mujer que no esperó su signo y que por propia decisión cruzó la frontera que no nos es dado cruzar sin ser llamados? Esta duda sólo tiene sentido en el supuesto de la supervivencia espiritual más allá de la muerte física, pero ¿y si no hay tal supervivencia? ¿Si no se es más allá de la tumba, pues todo acaba en ella? Esta es la segunda duda, la que asoma en la prótasis de esta oración condicional: "¿si es que eres?"

Hay siempre un alivio en saber, no importa lo doloroso que resulte. En este canto, ese alivio le es vedado al poeta: el destino final de Filí-Melé permanece en una doble desgarradora interrogante. 


\section{CANTO SEGUNDO: APREHENSION POR EL LENGUAJE}

El segundo canto es la "voz" del lenguaje, de la palabra. ¿La evocación no lograda por la fantasía onírica, debido a la distorsión y deformación propia de sus imágenes, podrá lograrse mediante la palabra? ¿Podrá la palabra aprehender, asir, esta imagen?

El canto está subdividido en dos partes: una primera parte (estrofa 5) expresiva del anheloso intento de aprehender - "asir"- por la palabra la imagen amada que se desea salvar del tiempo; y una segunda parte (estrofa 6) que es la patética confesión de impotencia para conseguirlo, acompañada del más desconsolador desgarramiento.

La primera parte constituye la más dramática e intensa expresión que conozca de la imposibilidad de la palabra para captar y transmitir los más íntimos y profundos estratos de nuestra sensibilidad. Los poetas de todas las épocas y pueblos nos tienen acostumbrados a esa verdad: a pesar de sus tenaces esfuerzos - "lucha de Jacob con el ángel", según la expresión de Alfonso Reyes-a todos queda la penosa desasosegadora sensación de que lo más hondo y valioso de su sentir no encontró cabida en la palabra y se quedó dentro. Con una sencillez inigualada lo ha expresado otro gran poeta puertorriqueño, José Antonio Dávila:

Huyendo de mi sombra y de un recuerdo, Loco en pensares $y$ en sentires cuerdo, derramé en la poesía mi agonía.

Mas veo al cabo que el sentir más hondo no se hizo verso; se quedó en el fondo iy siento que me ahoga todavía!

("Ex-Libris") $)^{3}$

El gran misterio de la poesía es expresar lo que no tiene palabras ya hechas para expresarlo, lo inefable. Para ello, las palabras, al contacto con la realidad psíquica que busca manifestarse, han de humedecerse de humores afectivos, que en

3 José Antonio Dávila, Vendimia. Poemas, (San Juan, Puerto Rico, Biblio. teca del Ateneo Puettorriqueño, 1940), p. 157. 
cierto modo las transforman, en forma tal que, siendo las mismas, son al mismo tiempo diferentes. Lo más sutil, y por lo mismo, volátil, de esos humores, no llega, sin embargo, a impregnar la palabra; apenas si la roza. Esa realidad psíquica me parece captada de manera extraordinariamente bella y exacta en los primeros ocho versos de la quinta estrofa:

\section{II}

En sombra de sentido de palabras, Fantasmas de palabras;

En el susto que toma a las palabras

Cuando con leve, súbita pisada

Las roza el halo del fulgor del alma

- Rasgo de ala en el agua,

Ritmo intentado que no logra acorde,

Abortada emoción cohibida de habla-...

Si ello es así, ¿ cómo encontrar, en medio de la soledad y el silencio, ya sea el silencio denso, casi palpable, de las noches estrelladas, o el plano y amarillo de las desiertas playas en que sólo el mar toca sobre el tambor de la arena, esa imagen inefable de la muerta amada? ¿Cómo lograr una imagen secundaria - en la palabra poética- de su imagen? Ese anhelo es el que se expresa en los restantes versos de la estrofa:

En el silencio $\tan$ cercano al grito

Que recorre las noches estrelladas,

Y más lo vemos que lo oímos,

$\mathrm{Y}$ casi le palpamos la substancia;

$O$ en el silencio plano y amarillo

De las desiertas playas,

Batiendo el mar en su tambor de arena

Salado puño de ola y alga,

¿Qué lenguaje te encuentra, con qué idioma

(Ojo inmóvil, voz muda, mano laxa)

Podré yo asirte, columbrar tu imagen,

La imagen de tu imagen reflejada

Muy allá de la música-poesía,

Muy atrás de los cantos $\sin$ palabras?

Pero, "en vano es luchar" que dijera Bécquer de su "himno gigante y extraño". Las palabras, o mejor "las sombras de 
palabras", esas que no llegaron a cuajar en expresión lingüística, y los deseos, como los galgos olfateando la pista, se alargan hacia la imagen amada, pero sin asirla, y el poeta queda roto $\mathrm{y}$ vencido:

Mis palabras, mis sombras de palabras, A ti, en la punta de sus pies ahupada Mis deseos, mis galgos de deseos, A ti, ahilados, translúcidos espectros. Yo, evaporado, diluído, roto, Abierta red en el sinfín sin fondo... Tú, por ninguna parte de la nada, ¿Qué escondida, cuán alta? (Estr. 6)

El segundo canto, pues, termina con una lastimosa confesión de la impotencia de la palabra para aprehender la imagen amada. Otra acción frustrada.

\section{CANTO TERCERo: el PENSAMIENTo IMAginativo}

En el pensamiento - no el lógico y discursivo, sino ese otro que Bally ha denominado "pensamiento vivido" y en el cual hay tanto de volición y de fantasía como de razón-; en el pensamiento inconsciente como flujo tan rápido, tan fugaz, que cuando la conciencia quiere detenerle, para fijarle, ya no existe, la imagen amada se ha ido tornando tan borrosa e imprecisa - "catedral de ceniza, árbol de niebla"-que es imposible su aprehensión: "¿Cómo subir tu rama? ¿Cómo tocar su puerta?"

En lo fugaz, en lo que ya no existe

Cuando se piensa,

$Y$ apenas deja de pensarse

Cobra existencia

En lo que si se nombra se destruye

Catedral de ceniza, árbol de niebla-

¿Cómo subir tu rama?

¿Cómo tocar tu puerta? (Estr. 7) 
A veces, a puro esfuerzo de imaginación, el poeta cree haber reconstruído la imagen amada, pero ésta, como si estuviese formada por la espuma del mar de la imaginación, se deshace en su propio oleaje. Todavía queda un consuelo para el poeta: puede que al sentimiento le sea posible lo que no le ha sido a la imaginación. $\mathrm{Y}$ se consuela pensando que su pena establece un vínculo afectivo que atravesando las barreras del tiempo y del espacio, penetra en el misterio y le une a ella. Sólo que este puente es tan frágil y quebradizo, que hasta un gesto o una mirada bastarían para destruirlo:

\footnotetext{
Pienso, Filí-Melé, que en el buscarte $\mathrm{Ya}$ te estoy encontrando

$Y$ te vuelvo a perder en el oleaje Donde a cincel de espuma te has formado. Pienso que de tu pena hasta la mía Se tiende un puente de armonioso llanto Tan quebradizo y frágil, que en la sombra Sólo puede el silencio atravesarlo Un gesto, una mirada, bastarían A fallar sus estribos de aire amargo Como al modo de Weber que en la noche Nos da, cisne teutón, su último canto. (Estr. 8)
}

Tres intentos infructuosos de revivir una imagen amada que se va desdibujando en la memoria por efectos del tiempo - "catedral de ceniza, árbol de niebla"-: "acción frustrada", fracaso. Pero, paradójicamente, ese fracaso es fuente de triunfo: porque al intentar, infructuosamente, asir la imagen evanescente, se ha creado una obra de belleza, un poema, que significa su salvación por la inmortalidad que confiere el arte y Filí-Melé, en el mundo de la poesía, pasa a ocupar un puesto junto a Beatriz, Laura, Helena y las demás amadas ilustres de la literatura. En esa forma, las tres "voces" de la "acción frustrada", son el sostén sobre que descansa esta puerta al tiempo que el poeta ha abierto en bien del doloroso recuerdo de la mujer amada:

Canto final donde la acción frustrada Abre al tiempo una puerta sostenida En tres voces que esperan tu llegada, 
Tu llegada aunque sé que eres perdida

Perdida y ya por siempre conquistada

Fiel fugada Filí-Melé abolida.

\section{FORMA Y ESTILO}

Por lo que se refiere a la forma externa, Puerta al tiempo en tres voces está compuesta fundamentalmente en endecasílabos con mezcla de algunos heptasílabos, enseasílabos y pentasílabos. La organización estrófica es completamente irregular tanto en lo que concierne a la combinación de metros (excepto en el primer canto) como al esquema de rima: hay estrofas todas en un sólo metro (primer canto), estrofas de endecasílabos, heptasílabos, y eneasílabos (segundo canto) y estrofas de endecasílabos, pentasílabos, heptasílabos y eneasílabos (tercer canto). En lo que a rima concierne, la del primer canto es consonante, pero sin esquema regular y aun con versos sueltos. En la del segundo y tercer cantos es asonante, con una tendencia a la rima alternada, pero, en rigor, sin esquema fijo y con versos sueltos. El efecto total es curioso, porque el ritmo mantenido por la emoción hace que esta diversidad métrica y de rima pase casi inadvertida para el lector.

En lo que respecta al estilo no disponemos de espacio para un análisis pormenorizado tal como el poema merece. Hemos de limitarnos a señalar la certera intuición con que el poeta ha sabido escoger los procedimientos y recursos adecuados a la manifestación de su temple anímico. Porque no cabe la menor duda; entienda o no el lector en sus pormenores el poema, la impresión general de la angustiosa procura de salvación para el recuerdo de la mujer amada hiere con una intensidad especial nuestra sensibilìdad y nuestra imaginación. Todo un mundo alucinante, dolorosamente transido de frustración, surge al conjuro de la palabra mágica del poeta.

El temple anímico - angustia rayana en la alucinación y el delirio- encuentra, a mi juicio, expresión especial en tres recursos que constituyen la armazón principal del estilo del poema: la interrogación, la imagen visionaria y la visión. ${ }^{*}$ La

+ Uso los términos "imagen vișionaria" y "visión" con la significación que 
importancia de la interrogación como manifestación del temple angustiado del poeta se hace evidente con sólo observar que, en rigor, desde la estrofa tercera a la séptima, el poema es una serie de interrogantes. $Y$ son esas preguntas, con su reiterado interrogar, las que ponen de relieve la incapacidad de aprehender la imagen amada, causa de la angustia del poeta. La imagen visionaria ("Sobre mares oleados de quimeras"; "Mis sombras de palabras"; "mis galgos de deseos/a ti, ahilados, translúcidos espectros"; "Yo, evaporado, diluído, roto,/ abierta red en el sinfín sin fondo"...) y la visión ("La flúida cabellera / Fronda crece, de abejas enjambrada; El tronco -desnudez cristalizada-/Es desnudez en luz tan desnudada/ Que al mirarlo se mira la mirada" o "Catedral de ceniza, árbol de niebla/¿Cómo subir tu rama?/¿Cómo tocar su puerta?”) crean la atmósfera de exaltación emotiva casi delirante que le da al poema ese aire alucinante que le caracteriza. A esta armazón fundamental se unen una gran diversidad de recursos -anáforas, juegos de palabras, hipérboles, metáforas, perscnificaciones, sinestesias, contrastes, etc.- que aportan su nota al efecto total contribuyendo a crear ese complejo y armónico todo que es el poema.

\section{CONCLUSIÓN}

En Puerta al tiempo en tres voces, de Luis Palés Matos, veo uno de los poemas más bellos de nuestra lengua en el momento actual. En él se da a perfección la exigencia fundamental de la auténtica poesía, la que Pfeiffer denominara "participación": el poema no nos "habla de" un temple anímico sino que nos hace partícipes de él, nos transmite la vibración del alma que lo creó, con tal eficacia, que la nuestra vibra al unísono. Desde la primera vez que se lo lee, ingenuamente y sin preocupación analítica alguna, se adueña de nuestra sensibilidad y nuestra fantasía. Lecturas posteriores, y una comprensión más honda, aumentan el goce.

les da Carlos Bousoño en su Teoria de la expresión poética, (Madrid, Editorial Gredos, 1952), p. 84-100. 
Compartir el goce estético disfrutado, hacer partícipes a otros lectores del surtidor de belleza que es este poema a través de las resonancias que en mi sensibilidad ha provocado, constituye la única pretensión de este breve trabajo.

ANGEL LUIS MORALES, Universidad de Puerto Rico, Río Piedras, Puerto Rico. 